\title{
The Measurement of International Experience as a Dimension of Board Indices: Concept for an Improvement
}

\author{
Lutz Sommer \\ Business Administration and Engineering, Albstadt-Sigmaringen University \\ Jakobstr. 1 - 72458 Albstadt, Germany \\ Tel: 49-7571-732-9531Ｅ-mail: sommer@hs-albsig.de
}

Received: March 2, 2012

Accepted: March 26, 2012

Published: July 15, 2012

doi:10.5430/ijba.v3n4p2

URL: http://dx.doi.org/10.5430/ijba.v3n4p2

\begin{abstract}
In recent years, the internationality of enterprises, relying on adequate management resources, has gained in importance. One resource is the "International Experience of the Board" which for lack of primary data very often can be measured on the basis of secondary data only. The lack of primary data on the one hand and the public interest on the other hand leads to the creation of partly simplified board indices based on more or less random measures / variables or compositions with limited informative value. The objective of this paper is to demonstrate the need for an improvement of such indices composed of secondary data and to develop a new concept for a board index ("InEx WE"). The new index is based on the available secondary data, too, and has to be seen as a suboptimal solution but in contrast to some other indices this index offers the advantage of subdividing "International Experience" into different subareas and separate weighting factors to improve its informative value. First results of a pilot study indicate an additional informative value.
\end{abstract}

Keywords: Global board index, International experience, Cultural management, Internationalization of a firm, Cross cultural management

\section{Introduction}

Internationalization of business is one of the critical strategic steps on a company's way to profit increase. To meet the complex challenges coming along with the internationalization process, top management teams (TMTs) need to possess relevant qualifications and to establish internal structures enabling them to successfully face the dynamics and imponderables arising in the context of international business activities (Ghoshal, 1987). Therefore, TMTs' information processing capacity is of crucial importance to any company that is planning to internationalize (Verneulen \& Barkema, 2002). According to Harrison \& Klein (2007), one of the basic requirements to improve this capacity is International Experience IE, as described by the well-known Uppsala model (Johanson \& Vahlne, 1977).

Based on an extensive literature review, scientists like Schmid and Daniel (2006) confirmed the relevance of internationalization in theory and came to the conclusion that (Schmid \& Daniel, 2006, p. 1): “...internationalization of the top management teams has been introduced as an additional variable in upper echelons research (e.g. Sambarya, 1996; Elron, 1997, Hambrick et al., 1998; Carpenter et al., 2001; Athanassiou \& Nigh, 2002)."

Despite the fact that International Experience is widely accepted as an important source of information processing capacity and its frequent use in a large number of studies there's still much to be investigated about this construct. In particular, the conceptualization and - closely related - the measurement of it are very often done in a simple way by using available secondary data due to the lack of primary data. As an example, some researchers simply count the number of years a manager has spent abroad or the number of foreigners in the company as an indicator for internationality of the board. For example, the consultancy Simon Kucher\& Partner (2011) stated in their latest research that 52 out of 187 DAX-executive committee members are foreigners (Simon Kucher\& Partner, 2011, p. 1) and therefore confirm a remarkable internationality of the executive committee members of DAX listed companies. No doubt, this is an acceptable way of measurement in case of lack of primary data, but there is room for improvement. A combination of different secondary data might offer a more differentiated insight.

The theoretical contribution of the paper at hand consists in the development of an improved index for measuring the International Experience (IE) of board members with a higher informative value than the existing ones can do. The implementation of such a new index is based on the upper echelons research (Hambrick et al., 1984) as well as on the resource and information processing theory (Harrison \& Klein, 2007). Its main purpose is to develop a conceptualization 
of International Experience which is differentiated enough and at the same time accounts for the difficulty of properly measuring experience. In particular, the following research questions will be dealt with:

What criteria have been used in the past to grasp International Experience (IE) as differentiated as possible (see LITERATURE REVIEW)?

How can these results be used to develop a meaningful International Experience Index (see HYPOTHESES / DEVELOPMENT OF THE INDEX)?

Testing of the developed International Experience Index by a pilot study (see TESTING) in preparation for a comprehensive survey.

\section{Literature Review}

According to Hambrick, Davison, Snell \& Snow (1998), dealing with uncertainty and complexity of the environment is part of TMTs' routine business as they have to process large quantities of information which often are confusing, ambiguous or even contradictory (Finkelstein \& Hambrick, 1996).

Some scientists are of the opinion that the extent of information-processing demands should be illustrated by governance structures and mechanisms (Henderson \& Fredrickson, 1996). A company's decision to internationalize will inevitably lead to increased complexity and uncertainty for its TMT (Astley \& Brahm, 1989). As a rule, this is true for all companies, especially for the smaller ones and particularly for multinational companies (MNCs) as their daily business automatically includes dealing with many different countries and cultural areas. As a consequence, TMTs of multinational companies need to have considerable information processing capacities (Pralahad \& Hamel, 1990). Of course, the diversity and complexity of international markets cannot entirely be reproduced in the composition of TMTs. However, it is clear that a great variety of nationalities, cultural backgrounds, and international experience offers a large pool of information sources, abilities and views.

Therefore, measuring board internationalization should be based on the knowledge about TMTs. According to Gregoric, Oxelheim, Randoy \& Thomsen (2009) the measuring is based on different characteristics like for example the degree of multinationality, international experience, international network ties, foreign language proficiency and cultural differentiation (Gregoric et al., 2009, p. 77). Schmid and Kretschmer (2005) contributed additional dimensions like international education (Schmid \& Kretschmer 2005, pp. 7 et seqq.).

Due to these results international experience needs to be investigated in detail in an additional part of the literature review. Beyond doubt, the aforementioned considerations clearly underline the particular relevance of International Experience (IE) as a critical resource on TMT level with regard to information processing capacity, as well. Several descriptive studies support this idea. As an example, a study conducted by the business consultancy Simon Kucher \& Partner examined the enterprises listed at the German stock index DAX on the basis of their business reports with regard to their internationality in 2005 (Lesch, 2005, p.2). Regarding a possible correlation between the indicators the descriptive data show that there is a huge discrepancy between the foreign sales $(68.1 \%$ in 2004) and the number of foreign executive board members (20.4\% in 2005), whereas the international work experience (63\%) is almost as high as the foreign sales (Lesch, 2005, p. 13 et seqq.; Sommer, 2009, pp. 97 et seqq.). Similar results have been documented by the consultants of EgonZehnder International (EgonZehnder International, 2008). They investigated the importance of international directors on boards of S\&P 500 companies in the United States of America. The boards' global capabilities were measured using three dimensions (EgonZehnder International, 2008) (Note 1):

Dimension 1: Percentage of directors who are foreign nationals

Dimension 2: Percentage of directors who have at least one international educational degree

Dimension 3: Percentage of directors who have meaningful international work experience

The authors come to the conclusion that the "... board's global capabilities are determined primarily by the presence of foreign nationals and board members with significant international work experience" (Egon Zehnder International, 2008, p. 13). These observations indicate that International Experience (IE) represents an important resource in managing international business. Other business consultancies like Spencer and Stuart (2010) publish the number of foreign board members as an indicator of IE. If we take a look in the above mentioned publications it is clear that there is a public interest in knowing, whether a company is managed by an internationally experienced board or not.

Not surprisingly, IE is a frequently used variable in many studies on internationalization. This raises the question what exactly IE means. First of all, it obviously has something to do with one's nationality. An individual who has lived and 
worked in several different cultural contexts clearly distinct from his or her original national background, has a higher level of IE (Hambrick et al., 1998) which in turn implies that he or she has a higher personal level of internationality.

Regarding the construct of International Experience (IE) there is a large body of research showing that this dimension has on the one hand different manifestations and on the other hand this manifestation could be measured in different ways. The following table merges the different manifestations of the dimensions, however, it is not exhaustive:

$<$ Table 1 about here>

Obviously, "International Experience" can be conceptualized in many ways. Solidifying these leads to distinct sources of what we generally call International Experience (cf. Schmid \& Kretschmer, 2005, p. 8 / cf. Table 1):

(1) "International work experience" versus "International Assignment" versus "Foreign Assignments" versus "Work Experience Abroad" (cf. Table 1): It seems that there exist different manifestations for the issue of "International work experience". All manifestations comprise work experience acquired during employments abroad. Since neither of the above mentioned authors employed the different manifestations concurrently - for example in the form of a multidimensional coverage concept - they shall be summarized in the term "International Work Experience" to simplify the matter.

(2) "International Education" versus "International Schooling" (cf. Table 1): Here, the previous explanations are applied correspondingly, however, the main focus is on education. Within the scope of this analysis we will refer to "International Education Experience" which comprises school education and university studies.

(3) "Experience in an international function or function with international responsibility" versus "International sales experience" versus "Experience in an international division" versus "Responsibility for an international department" (cf. Table 1): These manifestations are used to distinguish them from "International Work Experience", that is, international experience which was not necessarily acquired during an employment actually abroad (cf. Roth, 1995). In this context, a summary under the manifestation "Experience in an international function / division" shall also be given here.

(4) "Previous international culture-specific experience" versus "Experience in eight geographic regions" (cf. Table 1): These manifestations describe how culture-specific the international experience is with the first manifestation exemplarily referring to the experience with a country (Takeuchi et al., 2005, p.91) and the second manifestation rather applyingto experience with complete regions (Athanassiou \& Nigh, 2002, pp. 166 et seqq.). However, both have the idea of specific knowledge in common so that here a combination under the term of "International Culture-Specific Experience" seems reasonable.

(5) The manifestation "Career international functional business experience" by Athanassiou and Nigh (2002) couldn't be assigned clearly and was thus excluded from further consideration. A strong proximity to "Experience in an international function" can be assumed. The manifestation "International Experience Diversity of TMT members" was also excluded, since it doesn't refer to individuals but to the board as a whole (Greveet al., 2009, p.217). This manifestation could be assigned to "International Culture-Specific Experience" without its focus on the board as a whole. In summary the following manifestations can be compiled on the basis of the literature reviews: (a) International Work Experience; (b) International Education Experience; (c) Experience in an International Function/Division; (d) International Culture-Specific Experience; (f) International Non-work Experience.

This exemplary literature-based collection of manifestations for "International Experience" reveals that we are dealing with a dimension which is multidimensional itself, as already indicated by different authors like Roth (1995), Reuber and Fischer (1997) or Datta and Herrmann (2002). Obviously, "International Experience" can generally be differentiated according to the place of acquisition (for example domestic international division versus subsidiary abroad; close versus remote cultural area), according to subject matter (for example work experience versus non-work experience) or according to the mode of acquisition (the relevant period of life, for example, school, university or job).

In addition to the problem of the different manifestations there is the question of how to measure "International Experience". Gregoric et al. (2009) distinguished between different levels of measurement (Gregoric et al., 2009, pp.78 et seqq.):

(1) Simple form: International experience is expressed by a dummy variable - with or without experience, used by several authors like Reuber and Fisher (1997) or Tihany et al. (2000).

(2) Advanced form: Exact number of years spent abroad (Carpenter et al., 2001) or in an international department / division (Wally \& Becerra, 2001; Sambaraya, 1996). 
(3) Alternative form: Including "... the numbers of assignments abroad and the possession of a foreign university degree" (Gregoric et al., 2009, p. 78).

To date, the possibility of weighting such years abroad because of the need to include for example a cultural differentiation in the measuring of board internationalization is not widely discussed in literature.

\section{Hypotheses}

We will now use the results from the literature review to develop a framework for a more precise conceptualization and measurement of IE. This framework is based on several pillars:

(1) "International Experience" is regarded as an important factor in several facets of internationalization theory, such as degree of internationalization or international entrepreneurship. Thus, it clearly is significant from a scholar's point of view.

(2) As a rule, "International Experience" is - depending on the specification - measured on a ratio scale documenting the years spent abroad, or, respectively, in charge of a relevant function or on a nominal scale with a dichotomous character (for example yes/no).

(3) "International Experience" can be differentiated among other things according to local characteristics and with regard to contents as well as regarding the way of acquisition.

(4) "International experience" is applied in practice to make a statement about internationality with the users facing different problems both with regard to the availability of data and the measuring method:

- Primary data of the board are difficult to collect or can't be collected at all which leads to the fact that only secondary data (for example in the form of CVs) can be consulted for assessment.

- As a rule, secondary data are incomplete.

- The current measuring of experience is carried out, as a rule, by totaling the years of experience abroad, all with the same weighting factor regardless of different periods of life, cultures or functions in which these were acquired. Suggestions for differentiated measuring are available to a limited extent only.

- A consideration concerning measuring methods of the temporal reference of the experience in the perspective of the loss of knowledge is missing.

- There are no broadly accepted suggestions for a formalization of the correlation between the measurement category (e.g. years) and its weighting (e.g. according to cultures).

The above findings and problems, respectively, are summarized in the hypotheses below. To this, especially the already traced characteristics "place, contents and way of making experience" are discussed below and reviewed to that effect whether or not new deductions for the compilation of the dimension "International Experience" can be reasoned. The "time aspect" is added to the characteristics above. This aspect should describe the possibility of loss of knowledge over time, which is established in science (Wixted \& Ebbesen, 1994, pp. 409 et seqq.; White, 2001, pp. 193 et seqq.). In concordance with many authors who have discussed IE, our major assumption is that the number of years spent abroad basically is an acceptable proxy variable to determine internationality in general. But due to the aforementioned characteristics, this number has to be modified in order to arrive at a more differentiated - and thus more realistic measure.

Characteristic 1 - regarding the way of acquisition ("How"): Following Hasselhorn and Gold (2006) the acquisition of "International Experience" shall be conceived in the form of learning. They define learning as "... a process, in which outlasting changes in the behavior potential as a result of experiences occur" (Hasselhorn \& Gold, 2006, p. 35). Here, it can also be differentiated between the different learning phases of a person in the scope of his or her socialization. The socialization can be defined "... as the process of origin and development of a personality in mutual dependency on the socially communicated social and material environment" (Geulen \& Hurrelmann, 1980, p. 15). Authorities for socialization are - depending on the period of life - for example family, playschool, school, media, employers and colleagues or politics. Rutter et al. (1979) describe that pupils spend about 15.000 hours at school which means that school is beside family the most important development environment. Therefore, the importance of school time in an international environment is strongly emphasized. Equally important is the professional world as a survey carried out by Baethge (1988) shows. According to this survey half of the young adults grant a high significance to their work with regard to their concept of life (Walter, 1995, p. 45). Insofar, it can be assumed that the respective periods of life are differently formative in the context of internationalization. In the framework of this analysis we will distinguish between 
"Work Experience (WE) and Non-work Experience (NWE)". With regard to the periods of life we will distinguish between non-work periods of life (e.g. school and family) and work periods of life (e.g. studies/education, career entry, management and top management). Studies / education can be counted as part of the work period due to the fact that they prepare for the job. Furthermore, latest scientific papers confirm a positive relation between international studies / education and international employment (Bundesministerium für Bildung und Forschung 2009; European Commission Education \& Training, 2011). Another way of differentiation is to distinguish between "Continuity (CO) and Discontinuity (DCO)" of the willingness to gain International Experience (IE). However, this is not the subject of investigation for the paper at hand.

Characteristic 2 - regarding contents ("What"): According to Polanyi (1966), among others, knowledge can be differentiated into explicit knowledge, i.e. knowledge contents, which a person is aware of and which are available and can be communicated, and implicit knowledge, which is internalized but not cognizant or available as it is in the above mentioned form. A further form, which is differentiated in the scope of mnemonic research, is the short-term and long-term knowledge, the latter being differentiated into declarative knowledge (= recordable factual knowledge) and procedural knowledge (= courses of action that are difficult to describe). Due to the fact, that only secondary data, generally in the form of CVs, are available, which makes a classification in the above mentioned sense impossible, it must be assumed that declarative and procedural knowledge is existent. However, depending on experience on different management levels the knowledge may vary considerably. For example, Katz (1955) distinguished between lower, middle and upper management levels (Northhouse, 2010, p. 65). In general, it can be differentiated between management-close and management-remote "International Experience" with regard to "Management Experience" in an intercultural context - to be conceived as knowledge about the ".... combination of knowledge, insights and skills which are necessary for adequately dealing with national and regional cultures" (Burggraaf, 1998, as quoted in Rothlauf, 2009, p. 14). In the context of information processing capacity, this idea is of particular relevance as obviously not all kinds of international work experience increase an executive's ability to manage international business. We therefore argue:

Hypothesis 1: An unweighted and undifferentiated summation of years of international employment leads to significant contortions with respect to evaluating "International Work Experience" regarding its contribution to information processing capacity.

Characteristic 3 - regarding the place ("Where"): Here, differentiation can be made between the acquisition of "International Experience" in the home country on the one hand and the acquisition abroad on the other hand. Further, we can differentiate between the acquisition of international experience in the same cultural area and the acquisition outside one's own cultural area. For differentiation it can be divided to different subdivisions, e.g. to Hofstede' s (1980) four, respectively five cultural dimensions (Hofstede, 1980, 2001, pp. 351 et seqq.) or to the classification according to Huntington (1998) which comprises the following modified classifications of cultural areas: Sino-(China) - Japanese (Japan) - Hindu (India) - Islamic (undefined) ) - Slavic/Orthodox (Russia) - Western (USA) - Latin American (undefined) - African (undefined). The GLOBE Study, initiated by House (1991) offers another approach which tries to develop a theory about cultural differences in management styles and organizations. Following Hofstede, nine cultural dimensions were developed and six leadership dimensions were added (House, Hanges, Javidan, Dorfman \& Gupta, 2004). Thus, the present analysis is derived from at least three approaches. Based on the explanations above, it becomes clear that "International Experience" has to be assessed differently with regard to either the cultural proximity to, or the cultural distance from the home country, and in accordance with different authors (Gregoric et al., 2009, p. 79; Schmid \& Daniel, 2006, p. 7). The higher the cultural diversity a manager has experienced is, the higher is his ability to deal with the challenges different cultural contexts induce. Accordingly, an individual's "Cultural Experience" has to be assessed or weighted in a differentiated way which leads to the following hypothesis:

Hypothesis 2: Equalizing diverse and heterogeneous cultural experience through an unweighted summation of years spent abroad leads to significant contortions with respect to evaluating "International Work Experience"regarding its contribution to information processing capacity.

Characteristic 4 - regarding time ("When"): A subject will be remembered less and less as time goes by. The process of forgetting is not linear, but curvilinear (Wixted \& Ebbesen, 1991, p. 409). The authors discussed several possible forgetting functions like linear or logarithmic ones. The results of their study can be summarized as follows: "... the present results appear to favor the power function $(\mathrm{y}=\mathrm{a} * \mathrm{t}-\mathrm{b})$. Whether we consider recall, recognition, or savings as measures of memory, present words, faces, nonsense syllables, or graphic images as to-be-remembered material, use pigeons or humans as subjects, or employ seconds, days, or weeks as retention intervals, the result is the same" (Wixted \& Ebbesen, 1991, p. 413). Also, authors like Huber and Power (1985) and especially White (2001) confirmed in their articles about forgetting functions the dominance of exponential functions as the favored description (White, 2001: 193 
et seqq.). Based on the above explanations it can be assumed that the experiences over time are not stable. These considerations are in accordance with the conclusions of Takeuchi et al. (2005) who for managers distinguish "near and far knowledge transfer" (Takeuchi et al., 2005, p. 96). It is also stated that the type of learning and stimuli influences the forgetting curve in the field of immediate and intermediate recall of information, but there is no significant influence regarding longer retention intervals (Fioravanti \& Di Cesare, 1992, p. 121). Furthermore, it is obvious that a straight exponential forgetting curve would not be appropriate to express the forgetting approach, because not all memories fade out at the same rate and there are also memories that will never fade (Silkström, 2002, p. 143). Despite the still on-going discussion in literature about the most accurate model, there is a consensus about the fact that a curve is the appropriate illustration for the forgetting aspect. Additionally, it is undeniable that forgetting exists, only the principles the forgetting process follows are a very controversial field of research. A commonly used model is the power function which delivered the most accurate forgetting curve for a broad data collection (Averell \& Heathcote, 2011, p. 33). Therefore, in this article the power function is used as the most common model for the forgetting aspect. Out of this the following hypothesis can be deduced:

Hypothesis 3: Equalizing old and newly gathered experience through an unweighted summation of years spent abroad leads to significant contortions with respect to evaluating "International Work Experience" regarding its contribution to information processing capacity.

In addition to the forgetting aspect the learning aspect could be examined as well. Naim and Towill (1993) presented a family of transfer-function based learning curves. In view of the limited resources for this article we decided to base the paper at hand on simple assumptions with regard to the learning effect.

Characteristic 5 - regarding motivation ("Why"): The question of motivation can be seen as a relevant aspect of gaining international experience. The differentiation between intrinsic and extrinsic motivation seems reasonable for the evaluation of motivation but for lack of primary data it doesn't make sense to pursue this aspect of international experience.

Summarizing these considerations, it can be assumed that the summation of the indicator "Years abroad or International Function (Y), respectively" relativizes itself considering in which "management, culture and time relevance" these experiences were gathered. In other words: evaluating how relevant certain experiences really are for a manager's information processing capacity in terms of international business has to consider several factors obviously influencing the breadth and strength of these experiences. No doubt, an extension by other factors is possible and therefore subject of further research.

\section{Development of the Index}

The hypotheses developed above will now be examined in depth in a two-way procedure. First, the author presents a Work Experience (WE) oriented index which aggregates selected International Experience (InEx) to a single value. This index called $\mathrm{InEx}_{\mathrm{WE}}$ sums up the years spent abroad (Y) weighted by normalized (norm) factors like management relevance (MR), cultural relevance (CR) as well as time relevance, separated in learning effect (LE) and forgetting effect (FE). This listing comprehends the results from the previous chapters. Due to its orientation Non-work Experience (NWE) is not part of the paper at hand. Second, a pilot study will be carried out which compares this new index to an undifferentiated measure of international experience (i.e. simply adding up years) - based on the curricula of six people having clearly different international backgrounds.

Learning Effect (LE): This sum of years spent abroad (Y) could be seen as a simple indicator for intercultural learning. Schmid and Daniel (2006) suggested in contrast the following: "...A logarithmic function better corresponds to theories of intercultural learning than does a linear function" (Schmid \& Daniel, 2006, p. 16). Schmid and Daniel give further reason by pointing out that "... short stays abroad can have a large impact on intercultural sensitivity and awareness while after some years the learning curve flattens and additional time spent abroad only leads to limited additional effects" (Schmid \& Daniel, 2006, p. 16). For the paper at hand we don't follow this argumentation. A logarithmic function is only one option beside a family of transfer-function-based learning curves (Towill \& Naim, 1993, p. 330). The use of such a logarithmic function could be seen also as a simplification in contrast to s-shaped curves. Latest research confirmed the diversity of curves, e.g. Willcocks (2011) detected an s-shaped curve in the outsourcing context (Willcocks, 2011, p. 9). Furthermore it could be argued, that a logarithmic function overrates the first years of International Experience (e.g. 10 years of experience generate an index of 0.91 and 5 years of 0.83 ). The knowledge gap in regard to international learning curves leads to the assumption that it would be advisable to keep it simple and use a linear function. The result is a normalized multiplier LE IE-norm with the value 1. 
Management Relevance (MR): The consideration of different levels of experience, for example the level of a student compared to the level of a top manager in a company's board shall be taken into account by using a commonly valid differentiation criterion: the difference in salary. This surely is proportional to the information processing requirements a certain position entails as the salary is the amount of money a certain person's performance is worth to fulfill the activities associated with this position in the view of the shareholders. Thus, salary integrates to a certain extent job complexity. Successfully dealing with this complexity will probably increase a manager's information processing capacity. An enterprise's variable willingness to pay for a resource that has to be obtained - here management competence - shall serve as a benchmark for the significance of the task. The differences in salary "Salary Differentials SD" were compared which ranged from an annual average income for a management intern / undergraduate student up to an annual average income for a board member. If you determine for example the lower range of $S_{B}=10,000 €$ as basic value and apply to this the weight "1" then the maximum weight is at "140" if it is assumed that $S_{\mathrm{i}}=1.4$ million $€$ is the comparative value for the current salary of the considered manager as the following formula makes clear:

$$
\mathrm{SD}_{\mathrm{IE}}=\frac{\mathrm{S}_{\mathrm{i}}}{\mathrm{S}_{\mathrm{B}}}
$$

Legend: $\mathrm{SD}_{\mathrm{IE}}=$ Salary Differentials; $\mathrm{S}_{\mathrm{i}}=$ Salary in the relevant period $\mathrm{E} ; \mathrm{S}_{\mathrm{B}}=$ Baseline Salary

Depending on the location of the headquarters of the parent company - for example Germany - adequate basic data on the structure of salaries in regard to average salaries ranging from bachelor students to top managers have to be determined. In addition to the salary aspect it has to be clarified which classifications of management levels should be used for this research study. For example, the Encyclopedia of Business differentiates between three levels: top-level, middle-level and first-level (www.referenceforbusiness.com, 2011). This classification is similar to the early version of Katz (1955) or the St. Gallen-Management-Model of the University of St.Gallen, published in the seventies (Ruegg-Sturm, 2004). Mayer-Raven e.g. differentiates between four levels (Mayer-Raven, 1996, pp. 14-16). Without doubt, in literature there exists a multitude of models. A differentiation of management levels seems to be broadly accepted and therefore consequential international experiences should be also distinguished in levels. Board members with international experience as first-level managers are not comparable with those on top-level. For the paper at hand we will differentiate between the following levels based on the assumption that "effective leadership depends on three basic personal skills: technical, human, and conceptual" (Northouse 2010, p. 65): Beginner - without relevant leadership experience / Lower Level Manager - technical and human skills / Middle Level Manager - technical, human and conceptual skills are comparably relevant / Upper or Top Level Manager, respectively - technical and conceptual skills are prominent (Northouse 2010, p. 65). In the paper at hand the Undergraduate Student or Intern, respectively, is introduced as an additional level to cover International Work Experience at an early stage of the career also. To prevent devaluation between different levels - based on salary differentials, which are partly causeless - we use the logarithmic index based on Schmid and Daniel (Schmid \& Daniel, 2006, pp. 14-15). The result is a normalized multiplier SD $\mathrm{IE}^{-}$-norm with a value between 0 and 1 .

Cultural Relevance (CR): In corresponding studies Hofstede (1980) and House et al. (2004) documented the fact that cultural differences (CD) exist and that these differences can be determined. The cultural concept developed by Hofstede (1980) consists of four dimensions. His abstract was further developed to an index number for cultural distance by Kogut and Singh (Kogut \& Singh, 1988, p. 422):

$$
\mathrm{CD}_{\mathrm{IE}}=\sum_{\mathrm{i}=1}^{4} \frac{\left(\mathrm{I}_{\mathrm{ij}}-\mathrm{I}_{\mathrm{ih}}\right)^{2}}{4 \mathrm{~V}_{\mathrm{i}}}
$$

Legend: $\mathrm{CD}_{\mathrm{IE}}=$ Cultural Difference for International Experience IE; $1_{\mathrm{ij}}=$ Index of the cultural dimension $\mathrm{i}$ abroad $\mathrm{j}$; $1_{\mathrm{ih}}=$ Index of the cultural dimension in the home country $\mathrm{h} ; \mathrm{V}_{\mathrm{i}}=$ Variance of the index of dimension $\mathrm{i}$

However, this kind of abstract is not without controversy, the more so as Hofstede himself advises against the simple aggregation of data (Hofstede, 2001, p. 17). For want of other suitable solutions and considering that in spite of its deficiency the index of Kogut and Singh is currently widely used (Lee, Shenker, \& Li, 2008, p. 1120; Mulok \& Ainuddin, 2010 , p. 27) this approach has been accepted for the purpose of this paper. To determine cultural difference or cultural distance, respectively, the values of Hofstede' s cultural dimensions (except for the dimension "Long Term Orientation", as there exists only a limited data set) shall be used. They are available on Hofstede's website. To prevent a disproportional devaluation of International Experience (IE) from countries with a lower level of CD we use the 
logarithmic index (Schmid \& Daniel, 2006, pp. 14-15). The result is a normalized multiplier CD IE-norm with a value between 0 and 1 which seems to be a good compromise with the above mentioned controversy.

Forgetting Effect (FE): Considering the temporally contingent loss of knowledge it shall be reverted to the Forgetting Function on the basis of a Power Function $X=a^{*} t-b$ which was devised by Wixted and Ebbesen (1991). It is then inserted into the Proportion Correct function "PC" (Wixted \& Ebbesen, 1991, p. 413). The values are between 0 and 1 (normalization):

$$
F E_{[E-n o r m}=P C_{[E-n o r m}=\frac{\left(a \times t^{-b}\right)+1}{\left(a \times t^{-b}\right)+2}
$$

Legend: $\mathrm{FE}_{\mathrm{IE}-\text { norm }}=\mathrm{PC}_{\mathrm{IE}-\text { norm }}=$ Proportion Correct for International Experience IE; $\mathrm{a}=$ Factor; $\mathrm{b}=$ Factor; $\mathrm{t}=$ moment of consideration

For the factors the values " $\mathrm{a}=30$ " and " $\mathrm{b}=1$ " were assumed. This assumption is based on the Retention Curve for Recall Vocabulary by Bahrick (1984) or Bahrick et al (1993), respectively, which was included in the framework of a life-span analysis. In this context 773 persons were interviewed whose participation in language courses dated back differently long. The range varied from current participation (pupil) to a participation 50 years back (former graduates). This especially qualifies the study for the present paper, as on the one hand an examination of activities dating far back is possible and on the other hand fields of knowledge bordering on the intercultural environment were examined. The progress shows that the Percent Correct Recall was over 50\% for participants with a maximum time-lag to the course of 49 years. According to the results the curve progression of the Proportion Correct function (PC) was modeled by the factors "a" and "b". In other words: Which part of the knowledge generated by experiences made abroad at a certain point in time is still available?

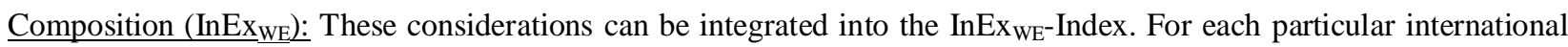

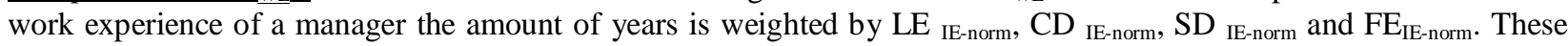
products are summed up over all distinct international work experiences. A manager without any international work experience would thus have an $\mathrm{InEx}_{\mathrm{WE}}$ value of 0 . The theoretical maximum value equals the length of the manager's career in years. Please note that $\mathrm{CD}_{\mathrm{IE}}$ and $\mathrm{SD}_{\mathrm{IE}}$ refer to the point in time where the experience has been made, whereas $\mathrm{FE}_{\mathrm{IE}}$ is rather related to the present. The following formula represents the InEx $\mathrm{WE}_{\mathrm{WE}}$ :

$$
\mathrm{InEx}_{\mathrm{WE}}=\sum_{\mathrm{IE}=1}^{\mathrm{n}}\left[\mathrm{Y}_{\mathrm{IE}} \times \mathrm{LE}_{\mathrm{IE}-\text { norm }} \times\left(1-\frac{1}{\mathrm{CD}_{\mathrm{IE}}+1}\right) \times\left(1-\frac{1}{\mathrm{SD}_{\mathrm{IE}}+1}\right) \times \mathrm{FE}_{\mathrm{IE}-\text { norm }}\right]
$$

The following formula could be seen as an alternative scientific notation with normalized multiplier:

$$
\operatorname{InEx}_{W E}=\sum_{\mathbb{E}=1}^{\mathrm{n}} \mathrm{Y}_{\mathrm{IE}} \times \mathrm{LE}_{\mathrm{IE} \text {-norm }} \times \mathrm{CD}_{\mathrm{IE} \text {-norm }} \times \mathrm{SD}_{\mathrm{IE} \text {-norm }} \times \mathrm{FE}_{\mathrm{IE} \text {-norm }}
$$

Legend: InEx $\mathrm{wE}_{\mathrm{E}}=$ International Work Experience Index; $\mathrm{Y}=$ International Work Experience in years; IE $=$ International Experience, where $\mathrm{n}$ is the complete set of these experiences; CD =Cultural Differences; Distances; SD = Salary Differentials; FE = Forgetting Effect; LE = Learning Effect

\section{Testing - Pilot Study}

To compare both ways of measuring IE we will use an anonymized data set of 75 DAX / M-DAX board members (period under review: 2009) for a pilot study to get first implications in regard to the differences of the methods. In the following, the curricula vitae of 6 additional board members are selected for illustration. Group A contains the persons A-1, A-2 and A-3 each with four years of experience abroad and Group B the persons B-1, B-2 and B-3, each with eight years of experience abroad. The curricula are based on commercial databases and agencies, but in this paper they are anonymized for the sake of privacy. In particular, we used for example internet sources like Thomas Reuters One Banker, Newsweek, Manager Magazine, Financial Times, Spencer-Stuart, Fortune, Bloomberg-Business Week and so on and combined the results. From these, the following information about international experience of board members was taken:

(1) Length of International Experience in years (Y): The following table provides the length of the respective stay abroad in years (Y) as well as the point in time of the acquisition in years from the current point of view, for example 15 years ago:

$<$ Table 2 about here> 
(2) Learning Effect (LE): The learning effect based on the assumption of a linear learning curve with the value of 1 for the multiplier $\mathrm{LE}_{\mathrm{IE}-\mathrm{norm}}$.

(3) Cultural Relevance (CR) is composed using the index of Kogut and Singh (1988) based on the Cultural Dimension of Hofstede (2001). Germany is the home country of the persons in the above mentioned sample. For a top manager / board member with cross-national functions, an average of the different CD values should be configured. The following cultural distances were collected in the framework of the pilot study: Germany Philippines (2.56) / Germany - China (2.53) / Germany - USA (0.41) / Germany - India (1.44) / Germany Switzerland (0.03) / Germany - Malaysia (3.80). The test persons' notional activities abroad in years combined with the pairs of countries where cultural distance was measured are entered in the following table:

$<$ Table 3 about here>

(4) Management Relevance (MR) comprises the differences in the test persons' salary during the different phases of their advancement towards the top management position. From the German point of view (homeland) the following values were assumed for the annual salary of the respective position: the salary of an Intern is at about 10,000 € (e.g. Marketing Consulting - Vipex Media Services GmbH, 2010) which corresponds to the salary of Undergraduate Students; the salary of graduate students (bachelor graduate) corresponds to the salary of a Beginner with 40,000 $€$ (e.g. Frankfurter AllgemeineZeitung FAZ, 2010b); the salary of a Lower Level Managers and Middle Level Managersamounts to $100,000 €$ up to $140,000 €$ (e.g. Recruiter Step Stone GmbH, 2010.); the salary of a Top Level Managers differs between 1.4 million $€$ for a Chief Executive Officer (CEO) on average (e.g. Frankfurter Allgemeine Zeitung FAZ, 2010a) and 0.7 million $€$ on average for an regular Board Member (Bundesanzeiger Verlag, 2010). From that the following Salary Differentials (SD) for each management level are derived: Interns / Undergraduate Students get the value 1; Graduate students / Beginners get the value $4(\mathrm{SD}=40,000 € / 10,000 €=4)$; Lower Level Managers get the value 10; Middle Level Managers get the value 14; Top Level Managers get the value 70 for regular Board Members and 140 for a CEO. Provided that the real wages for each position are available, individual $\mathrm{SD}$ values can be calculated.

(5) Forgetting Effect (FE) comprises the forgetting curve with the sub-function $X=30 * t-1$. For the notional experiences the following values were comprised in consideration of the acquisition moment, considered at the current point in time: Experiences made 30 years ago have a PC respectively FE value of 0.666 which means that about $66 \%$ of the acquired knowledge is still available at present; experiences that are 25 years old have a value of 0.688 ; 15-year-old experiences: $0.75 ; 10$-year-old experiences: $0.80 ; 5$-year-old experiences: $0.875 ; 1$-year-old experiences: 0.969 .

\section{Results}

Using the International Work Experience Index formula $\mathrm{InEx}_{\mathrm{WE}}$, the following values can be determined by inserting the data from the pilot study:

$$
\mathrm{InEx}_{\mathrm{WE}}=\sum_{\mathrm{IE}=1}^{\mathrm{n}}\left[\mathrm{Y}_{\mathrm{IE}} \times \mathrm{LE}_{\mathrm{IE}-\mathrm{norm}} \times\left(1-\frac{1}{\mathrm{CD}_{\mathrm{IE}}+1}\right) \times\left(1-\frac{1}{\mathrm{SD}_{\mathrm{IE}}+1}\right) \times \mathrm{FE}_{\mathrm{IE}-\text { norm }}\right.
$$

Legend: $\mathrm{InEx}_{\mathrm{WE}}=$ International Work Experience Index; $\mathrm{Y}=$ International Experience in years; IE $=$ International Experience in periods of time from 1 to $\mathrm{n}$; $\mathrm{CD}=$ Cultural Differences; Distances; / SD = Salary Differentials; FE = Forgetting Effect; LE = Learning Effect

\section{<Table 4 about here>}

The following example shall illustrate the calculation: Person B-3 currently works for the board of a German enterprise. In the context of his "International Experience" he had a 3-year-contract as a Low Level Manager in China (CD: 2.53) 15 years ago. 5 years ago he had a 5-year-contract as a Top Level Manager / Board Member for the Asian business area with a main focus on India (CD: 1.44). This manager has no further experience abroad. Regarding the Salary Differentials, a SD value of 10 for the manager position and a value of 140 for the board position are assumed. For the experiences 15 years ago the FE value is 0.75 , for the experiences 5 years ago it is 0.875 . From that the following calculation can be derived:

$$
\begin{aligned}
\operatorname{InEx}_{\mathrm{WE}}= & \{3 \text { years } * 1 *[1-1 /(2.53+1)] *[1-1 /(10+1)] * 0.75\}+\{5 \text { years } *[1-1 /(1.44+1)] * \\
& {[1-1 /(140+1)] * 0.875\} } \\
\operatorname{InEx}_{\mathrm{WE}}= & 4.03
\end{aligned}
$$


Thus, person B-3 has the most significant "International Experience" according to the formula above. In other words: from an information processing capacity point of view, i.e. the international management competence required on the board, this person is the most interesting resource. The results for the data set of 75 board members are presented in Table 5:

$<$ Table 5 about here>

The result shows in general a difference of $56 \%$ on average between the InEx $x_{\mathrm{WE}}$ and $\mathrm{Y}_{\mathrm{IE}}$-Total (= summation of $\mathrm{Y}_{\mathrm{IE}}$ ). The values of $\mathrm{InEx}_{\mathrm{WE}}$ and $\mathrm{Y}_{\mathrm{IE}^{-}}$Total are comparable to the small sample with 6 board members, which we was used for illustration.

\section{Discussion}

The following conclusions for the person group A can be drawn from the results at hand (see table 2-4):

(1) The weighted "International Experience" makes clear that the number of years spent abroad is not sufficient as sole indicator for "International Experience". In person group A all persons have the same number of years however, there are considerable differences with respect to the Management Relevance (MR) of the experience.

Person A-2: Here, the focus of experience is on the first years / studies, however, professional experience on management or top management level is missing, but the value of 2.00 is comparable to the value of Person A-1 (1.91). This fact could be explained by the high CD value of 3.80 (Low Level Manager).

Person A-1: The value of 1.91 based on the broad management experience. The CD value is lower in comparison to A-2.

Person A-3: Here, the focus of experience is clearly on the level of a manager / top manager. Thus the weighted value of 2.53 is the highest in this group.

In summary, it can be established that without considering the weighting of the management experience a significant contortion occurs which could be seen as a first support of hypothesis 1 . The results are also in line with the larger sample (see table 5). Board members with a similar value of four years of International Experience ( $\left.\mathrm{Y}_{\mathrm{IE}}\right)$ generate an InEx $_{\mathrm{WE}}$ which differs from $\mathrm{Y}_{\mathrm{IE}}$ with a deviance between $24 \%$ and $70 \%$. This is an additional support of hypothesis 1. Support could also be found for longer periods of experience, e.g. eight and sixteen years (see table 5).

(2) In addition to the management relevance, Cultural Relevance (CR) which is also included in the weighting is of importance as well.

Person A-2: In spite of a significantly lower level of international management experience, a beginner's level to be specific, it has, however, a positive impact in summation because of the high Cultural Distance (Germany - Malaysia: 3.8 ) and provides a value which is close to the one of A-1 with a lower value for the Cultural Distance (Germany India: 1.44; Germany - China: 2.53).

In summary, it can be stated that without considering the weighting of the cultural experience a significant contortion occurs which can be seen as a first support of hypothesis 2 . The results are supported by the larger sample as well.

(3) Forgetting Effect (FE) provides a further contribution to the differentiation of years as a measured variable for "International Experience".

Person A-2: Beginner's experience of 10 years in Malaysia is weighted with the factor 0.8 whereas the experience of A-3 (top manager) of 1 year is valued with 0.969 .

The Forgetting Aspect can also be considered to be supported by hypothesis 3, because without the weighting significant contortions occur. Similar results are obtained for the larger sample. Please note that knowledge not only suffers from forgetting: knowledge needs to fit actual requirements of the business world. Rather old experiences are more likely to be obsolete even if they are still recallable by the manager. This consideration maybe should lead to an even stronger devaluation of knowledge acquired years ago.

For person group B similar conclusions can be drawn, however, the following features shall be mentioned separately:

Person B-2: The lower value of 2.86 compared with 4.03 of person B-3 is explained by the combination of a low Management Relevance (MR) of 3 years and a lower Cultural Distance (CD) of 0.41 compared with 1.44. The experiences in the framework of the vocational preparation aren't a suitable alternative which can also be understood out of practical considerations. 
Person B-1: In this case the lower value of 2.30 is explained by the lower Cultural Distance gained from 3 years of experience as a Beginner in Switzerland (Germany - Switzerland: 0.03). A significantly higher value would have led to a total value comparable to B-2.

A comparison between the results of the person groups A and B also leads to relevant findings, as the example of A-3 and B-1 shows:

Person A-3: According to the summary table the weighted value for A-3 is 2.53 and for B-1 it is 2.30 , the latter having 8 years of experience abroad i.e.twice as many as A-3. However, this can easily be explained by the high level of top management experience and by the higher values for Cultural Distance (CD). The 3 years of experience as Beginner in Switzerland of person B-1 (CD-value: 0.03) are hardly of any relevance for the International Experience value.The sample of 75 board members shows a close similarity to the above mentioned results as well (see Table 5).

\section{Conclusion and Implications}

Despite the fact that in our pilot study we tested only two small sample sizes (= 6 and 75 Board Members), which are not representative, we were able to draw first conclusions in the sense of a comparison of different methods to measure IE. A confirmation or refusal of the hypotheses is impossible at this stage. Basically, InEx $\mathrm{WE}_{\mathrm{W}}$ allows computing IE in a much more differentiated way as it is possible by simply summing up years - an approach which is used quite often in literature. This is true despite the fact that this index contains some simplifications and proxy variables, too. InEx $\mathrm{WE}_{\mathrm{WE}}$ entails benefits for both the business and the science world. Science benefits from having a measure for IE which very likely reduces contortions induced by more primitive variables. This in turn can increase the quality of many models integrating IE, for example in the field of measuring internationality or International Entrepreneurship. Business on the other hand is provided with an easy-to-handle instrument which at least allows preliminary evaluation of an important facet of a manager's international business competence. This ordinary index InEx $\mathrm{WE}_{\mathrm{W}}$ allows its users (e.g. consultancies) first, to analyze the internationality of the board by using an available secondary data set in an uncomplicated way and second, to improve the informative value in comparison to other existing indices. No doubt, this index can't replace a primary data set based version, but it could be used as an alternative in some cases. In summary, the following conclusions result from the Literature Review and the application of the pilot study on $\operatorname{InEx}_{\mathrm{WE}}$ :

(1) Today, "International Experience" is still determined by most authors on the basis of the years spent abroad (Y) or an international function, respectively, for want of other reliable secondary data. The necessity to include "... psychological characteristics as cognitions, values and perceptions" (Schmid \& Daniel, 2006, p. 35) has been acknowledged to be important, but it is difficult to realize for lack of field research. This point leads to another simplification: experience is closely related to cognition, hence specific processes and constructs such as knowledge structure or the ability to recollect data from memory should be considered as well. However, this is difficult to measure and generally requires laboratory settings and thus is not applicable for daily use.

(2) There is a demand for specifically processed individual-related top manager data with regard to the determination of enterprise's internationality components.On the Human Resources sector such data is sought after for the assessment of individual persons. In the first case, this demand is met, as a rule, by secondary data (for example CVs) for lack of primary data. However, their analysis is difficult and partly leads to counterproductive simplifications in the compilation and analysis of the data. The $\mathrm{InEx}_{\mathrm{WE}}$ can provide first hints at an early stage for the desired quality of data by defining what is additionally required besides years spent abroad (Y). Consequently, the InEx $\mathrm{XE}_{\mathrm{WE}}$ can recommend the abandonment of the analysis if this basic data set consisting of years $(\mathrm{Y})$ and the weighting factors is not available. The index clearly supports a more differentiated and thus more precise consideration of IE. Especially quantitative studies will benefit from this approach as it is much closer to reality and thus more likely to increase transparency and model reliability.

(3) The inaccuracy which is caused by neglecting the weighting factors leads to a significant contortion of the compilation of "International Experience" in years (Y). Therefore, the application of the weighting factors is recommended, provided that the necessary data is available.

(4) When integrating the InEx $\mathrm{WE}_{\mathrm{W}}$ into a subordinate internationality index for the enterprise or the board of an enterprise it has to be considered that compatibility questions have to be clarified if there is a summarization with other indices or specific values, respectively. In other words: the weighting issue arises here extensively, too. 
Summing up, it could be concluded that the new index InEx $_{\mathrm{WE}}$ offers an improvement in measuring International Experience (IE) in regard to the existing indices in terms of the informative value. In addition, the paper demonstrates the danger of misinterpretation by simply structured indices.

\section{Limitations and Future Research}

The present analysis is subject to the following limitations:

(1) The sample size of the pilot study is quite small. However, it is good enough to demonstrate the general differences in measuring International Experience. A comprehensive analysis is recommended to confirm / refute the hypotheses on the one hand and to test the practicability of the developed InEx $x_{\mathrm{WE}}$ regarding the lack of data on the other hand.

(2) The assumption, that the years spent abroad (Y) or an international function, respectively, are a sufficient indicator for "International Experience" at all, is undoubtedly a simplification, whose validity still has to be examined by further analyses. This points at an important question in terms of International Experience: researchers and practitioners should ask what a manager really has learned during his stays abroad. Do we need a special learning curve?

(3) The assumptions about the weighting of International Experience above Salary Differentials (SD) also display a simplification. Do we need also for the SD a learning curve, which is different from the one, which we have used in the paper at hand?

(4) It also has to be taken in mind for the Salary Differentials (SD) that salaries differ according to the branches that are investigated and also that the seniority principle is, especially in the non-top management areas, an influencing factor.

(5) The objective of future analyses will be the detection of other suitable weighting factors. In particular, it should be made sure that the mathematical functions of these adaption factors are synchronous, otherwise an unintended weak effect of one factor might contradict another one. Furthermore, are the factors and underlying functions the same for all cases?

(6) The weighting of International Experience by using Hofstede's data (1980) and the index of Kogut and Singh (1988) generates three problems. On the one hand, Hofstede's data are not undisputed. However, InEx $x_{W E}$ allows the application of other data like the Globe Study of House et al. (2004), too. On the other hand, the index of Kogut and Singh (1988) is partly rejected as being unsuitable. However, here it can be referred to the fact, that no other suitable approaches are available. Both approaches lead to uncertainty concerning the informative value of the results and indicate the need for research. The Psychic Distance Index of Dow and Karunaratna (2006) or Brewer (2007) constitutes further possible options with regard to other weighting factors. The third problem based on the assumption of a logarithmic function for $\mathrm{CD}$, because the evidence is still outstanding. To sum up, there is some need for research here.

(7) Forgetting Effect (FE) also has its limitations which especially result from the functional modeling of the loss of knowledge. There are no studies which document the aspect of loss of knowledge in connection with "International Experience". The existing research work about loss of knowledge in relation to "International Experience" comprises, as a rule, only a range of limited conditions (for example language skills). And to complicate the matter, they generally have short periods of examination.

(8) Learning Effect (LE) should be part of future research. Non-linear learning curves cause a relevant impact on the results.

(9) The new index is based on the same inadequate secondary data like the other existing indices but the informative value is higher due to the comprehension of additional information like "Cultural Relevance (CR)" or "Forgetting Effect (FE)".

(10) Non-work experience (NWE) is not included in the index. The development of such an additional index $\left(\mathrm{InEx} \mathrm{x}_{\mathrm{NWE}}\right)$ is subject to additional research.

In spite of the described limitations it can be assumed, however, that the present index forms an improvement to the current state of knowledge and complements the agenda for future research in the field of "International Experience". However, more than a suboptimal solution can't be offered due to the poor secondary data quality, which is well-known in practice. 


\section{References}

Astley, W.G., \& Brahm, R.A. (1989). Organizational Designs for Post-industrial Strategies. The Role of Interorganizational Collaboration. In Snow, C.C. (Ed.), Strategy, Organization, Design, and Human Resource Management.Strategic Management Policy Planning. A Multinational Treatise (3). Greenwich, Conn./ London.

Athanassiou, N., \& Nigh, D. (2002). The Influence of the International Business Experience of the Top Management Team on the Internationalization of the Firm. Social Networks at Work. Management International Review, 42(2).

Averell, L., \& Heathcote, A. (2011). The form ofthe forgetting curve and the fate of memories. Journal of Mathematical Psychology, 55, 25-35. http://dx.doi.org/10.1016/j.jmp.2010.08.009

Baethge, M. (1988). Jugendarbeit und Identität - Lebensperspektiven und Interessenorientierungen von Jugendlichen. Opladen.

Bahrick, H. (1984). Fifty Years of Second Language Attrition - Implications for Programmatic Research. The Modern Language Journal, 68.

Bahrick, H., Bahrick, L., Bahrick, A., \& Bahrick, P. (1993). Maintenance of Foreign Language Vocabulary and the Spacing Effect. American Psychological Society.

Bloodgood, J.M., \& Sapienza, H. (1996). The internationalization of new high-potential U.S. ventures.antecedents and outcomes. Entrepreneurship Theory and Practice, 20(4).

Brewer, P. (2007). Psychic Distance and Australian Export Market Selection. Australian Journal of Management, 32(1), 73-94. http://dx.doi.org/10.1177/031289620703200105

Bundesanzeiger Verlag. (2010). Managergehälter 2010. [Online] Available: http://www.firmextra.de/wissen/aktueller-fachartikel/studie-managergehaelter-2010-aus-dem-bundesanzeiger-verlag/

Bundesministerium für Bildung und Forschung. (2009). Der berufliche Ertrag der ERASMUS-Mobilität. [Online] Available: http://www.bmbf.de/pub/erasmus_mobilitaet.pdf

Burggraaf, W. (1998). Intercultural Management - on cultures and the multicultural organisation. Nyenrode/ Netherlands: Nyenrode University.

Carpenter, M.A., \& Fredrickson, J.W. (2001). Top management teams, global strategic posture, and the moderating role of uncertainty. Academy of Management Journal, 44(3). http://dx.doi.org/10.2307/3069368

Carpenter, M.A., Pollock, T.G., \& Leary, M.M. (2003). Testing a model of reasoned risk-taking.Governance, the experience or principals and agents, and global strategy in high-technology IPO firms. Strategic Management Journal, 24.

Carpenter, M.A., Sanders, W., \& Gregersen, H. (2001). Bundling human capital with organizational context.The impact of international assignment experience on multinational firm performance and CEO pay. Academy of Management Journal, 44(3). http://dx.doi.org/10.2307/3069366

Carpenter, M.A., \& Westphal, J.D. (2001). The strategic context of external network ties.Examining the impact of director appointments on board involvement in strategic decision making. Academy of Management Journal, 44(4). http://dx.doi.org/10.2307/3069408

Daily, C.M., Certo, S.T., \& Dalton, D.R. (2000). International experience in the executive suite.the path to prosperity.

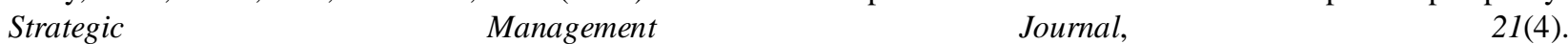
http://dx.doi.org/10.1002/(SICI)1097-0266(200004)21:4<515::AID-SMJ92>3.0.CO;2-1

Dow, D., \& Karunaratna, A. (2006). Developing a multidimensional instrument to measure psychic distance stimuli. Journal of International Business Studies, 37, 578-602.

EgonZehnder International. (2008). Global Board Index. Mango Strategy LLC, USA.

Egon Zehnder International. (2010, July 28). Contact with the headquarter of EgonZehnder International. Chicago, USA: Teri Schram.

Encyclopedia of Business. (2011). Management levels. [Online] Available: www.referenceforbusiness.com (December 20, 2011)

European Commission of Education and Training. (2011). Erasmus Student Mobility for Studies. [Online] Available: http://ec.europa.eu/education/erasmus/doc892_en.htm 
FAZ. (2010a). Managergehälter - So viel verdienen die Dax-Chefs nach der Krise. [Online] Available: http://www.faz.net/p/RubD16E1F55D21144C4AE3F9DDF52B6E1D9/Dox Ec5deca7a2d7c829adf5e6e124f666bf7 AT pl Ecommon Scontent.html (August 17)

FAZ. (2010b). Gehälter - Einstieg mit 40.000 Euro. [Online] Available: http://www.faz.net/artikel/C30513/gehaelter-einstieg-mit-40-000-euro-30086600.html (August 18)

Finkelstein, S., \& Hambrick, D.C. (1996). Strategic Leadership. Top Executives and Their effects on Organizations. West, Minneapolis \& St. Paul.

Fioravanti, M., \& Di Cesare, F. (1992). Forgetting Curves in Long-Term Memory: Evidence for a Multistage Model of Retention. Brain and Cognition, 18, 116-124. http://dx.doi.org/10.1016/0278-2626(92)90073-U

Geulen, D., \& Hurrelmann, K. (1980). Zur Programmatik einer umfassenden Sozialisationstheorie. In K. Hurrelmann, D. Ulrich (Ed.), Handbuch der Sozialisationsforschung (pp. 51-67). Weinheim: Beltz.

Ghoshal, S. (1987). Global Strategy: An Organizing Framework. Strategic Management Journal, 8(5). http://dx.doi.org/10.1002/smj.4250080503

Gregoric, A., Oxelheim, L., Randoy, T., \& Thomsen, S. (2009). Corporate governance as a source of competitiveness for Nordic firms. Norway: University of Agder, Nordic Innovation Centre.

Greve, P., Nielsen, S., \& Ruigrok, W. (2009). Transcending borders with international top management teams.A study of European financial multinational corporations. European Management Journal, 27, $213-224$. http://dx.doi.org/10.1016/j.emj.2008.10.001

Hambrick, D. C., Davison, S., Snell, S., \& Snow, C. (1998). When groups consist of different nationalities. Towards a new understanding of the implications. Organization Studies, $19, \quad 181-205$. http://dx.doi.org/10.1177/017084069801900202

Harrison, D.A., \& Klein, K.J. (2007). What's the difference? Diversity constructs as separation, variety, or disparity in organizations. Academyof Management Review, 32.

Hasselhorn, M., \& Gold A. (2006). Pädagogische Psychologie - Erfolgreiches Lernen und Lehren. Stuttgart, Germany: KohlhammerVerlag.

Henderson, A., \& Fredrickson, J. (1996). Information processing demands as a determinant of CEO compensation. Academy of Management Journal, 39.

Herrmann, P., \& Datta, D.K. (2002). CEO Successor Characteristics and the Choice of Foreign Market Entry Mode.An Empirical Study. Journal of International Business Studies, 33(3). http://dx.doi.org/10.1057/palgrave.jibs.8491031

Hofstede, G. (1980). Culture's Consequences - International Differences in Work Related Values. Newbury Park, London, Neu Delhi: Sage Publications.

Hofstede, G. (2001). Culture's Consequences - Comparing Values, Behaviors, Institutions and Organizations Across Nations. Thousand Oaks, London, Neu Delhi: Sage Publications.

House, R., Hanges, P., Javidan, M., Dorfmann, P. W., \& Gupta, V. (2004). Culture, Leadership, and Organizations. The Globe Study of 62 Societies. Thousand Oaks, London, Neu Delhi: Sage Publications.

Huber, G.P., \& Power, D.J. (1985). Retrospective reports of strategy-level managers: guidelines for increasing their accuracy. Strategic Management Journal, 6, 171-80. http://dx.doi.org/10.1002/smj.4250060206

Huntington, S. P. (1998). The Clash of Civilizations and the Remaking of World Order. New York: Simon \& Schuster. Jex, S. (2002). Organizational psychology - A scientist-practitioner approach. New York: John Wiley \& Sons Inc.

Johanson, J. \& Vahlne, J.-E. (1977). The Internationalisation Process of the Firm -A Model of Knowledge Development and Increasing Foreign Commitments. Journal of International Business Studies, 8(1), 23-32. http://dx.doi.org/10.1057/palgrave.jibs.8490676

Kogut, B., \& Singh, H. (1988). The effect of national culture on the choice of entry mode. Journal of International Business Studies, 19(3), 411 - 432. http://dx.doi.org/10.1057/palgrave.jibs.8490394

Lee, L.Y., \& Sukoco, B.M. (2007). The effects of expatriate personality and cultural intelligence on the expatriate adjustment. The moderating role of expatriate. In: Proceedings of the 13th Asia Pacific Management Conference. Melbourne, Australia. 
Lee, S., Shenkar, O.K., \& Li, J. (2008). Cultural Distance, Investment Flow, and Control in Cross-Border Cooperation. Strategic Management Journal, 29, 1117-1125. http://dx.doi.org/10.1002/smj.685

Lesch, C. (2005). Internationale Lenker, nationale Kontrolleure - Eine Untersuchung der Internationalität von Vorstand und Aufsichtsrat der DAX-Unternehmen. Bonn:Consultancy SIMON-KUCHER \& PARNTER.

Mayer-Raven, C. (1996). Funktionswandel im mittleren Management. Hochschulschrift Universität St, Gallen, 14-16.

Michel, J.G., \& Hambrick, D.C. (1992). Diversification Posture and Top Management Team Characteristics. Academy of Management Journal, 35.

Mulok, D., \& Ainuddin, R. (2010). Foreign Entry Mode, Cultural Distance and Subsidiary Performance of Malaysian Mnes. International Journal of Business and Management, 5(2), 26-31.

Naim, M. M., \& Towill, D. R. (1993). Modelling and Forecasting Industrial Innovations via the Transfer Function S-Shaped Learning Curve. International Journal of Advanced Manufacturing Technology, 8, 329-343. http://dx.doi.org/10.1007/BF01783617

Northouse, P. (2010). Leadership - Theory and Practice (5 ${ }^{\text {th }}$ ed.). SAGE Publication Inc., 65.

Polanyi, M. (1996). Knowing and Being. Great Britain.

Prahalad, C.K., \& Hamel, G. (1990). The core competences of the corporation. Harvard Business Review, 68(3).

Reuber, R., \& Fischer, E. (1997). The Influence of the Management Team's International Experience on the Internationalizations Behaviors of SMEs. Journal of International Business, 28(4). http://dx.doi.org/10.1057/palgrave.jibs.8490120

Roth, K. (1995). Managing international interdependence.CEO characteristics in a resource-based framework. Academy of Management Journal, 38(1). http://dx.doi.org/10.2307/256733

Rothlauf, J. (2009). Interkulturelles Management. München, Germany: Oldenbourg Verlag.

Ruegg-Sturn, J. (2004). The New St. Gallen Management Model: Basic Categories of an Integrated Management: Basic Categories of an Approach to Integrated Management. In: Palgrave.

Rutter, M., Maughn, B., Mortimore, P., Ouston, J., \& Smith, A. (1979). Fifteen Thousand Hours.Secondary Schools and Their Effects of Children. Cambridge, Mass: Harvard University Press.

Sambarya, R.B. (1996). Foreign Experience of Top Management Teams and International Diversification Strategies of U.S. Multinational Corporations. Strategic Management Journal, 17(9).

Schmid, S., \& Kretschmer, K. (2005). How International are German Supervisory Boards? - An Exploratory Study. Berlin: ESCP-EAP.

Schmid, S., \& Daniel, A. (2006). Measuring Board Internationalization - Towards a More Holistic Approach. ESCP-EAP Working Paper, No. 21. Berlin: European School of Management.

Sikström, S. (2002). Forgetting curves: implications for connectionist models. CognitivePsychology, 45, 95-152. http://dx.doi.org/10.1016/S0010-0285(02)00012-9

Simon Kucher \& Partner. (2011). DAX Führungsspitzen - Sehr international, aber kaum weiblich. [Online] Available: http://www.simonkucher.com/internetdatabase/Publication.nsf/0/31BB2C6CEE668827C12578DB0034B4D6

Sommer, L. (2009). Degree of Internationalization - A Multidimensional Challenge. The Journal of Applied Business Research, 25(3), 93-109.

Stuart and Spencer. (2011). Stuart Spencer Board Index. [Online] Available: http://www.spencerstuart.com//global

Step Stone GmbH. (2010). Manager: Gehalt nach Bereichen. [Online] Available: http://management-jobs.stepstone.de/content/de/de/b2c_Manager_Gehalt_nach_Bereichen.cfm

Takeuchi, R., Tesluk, P., \& Lepak, D. (2005). An integrative view of international experience.Academy of Management Journal, 48(1), 85-100. http://dx.doi.org/10.5465/AMJ.2005.15993143

Tihany, L., Ellstrand, A.E., Daily, C.M., \& Dalton, D.R. (2000). Composition of the Top Management Team and Firm International Diversification. Journal of Management, 26(6).

Vermeulen, G.A.M., \& Barkema, H.G. (2002). Pace, rhythm and scope; Process dependence in building a profitable multinational corporation. Strategic Management Journal, 23(7). http://dx.doi.org/10.1002/smj.243 
Vipex Media Services GmbH. (2010). Praktikum.de - Die Orientierung: Wie finde ich ein Praktikum, das zu mir passt. [Online] Available: http://www.praktikum.de/german/bewerberinfos/orientierung.html

Wally, S., \& Becerra, M. (2001). Top Management Team Characteristics and Strategic Changes in International Diversification.The Case of U.S. Multinationals in the European Community. Group \& Organization Management, 26(2). http://dx.doi.org/10.1177/1059601101262003

Walter, R. H. (1995). Beruf und Lebenslauf - Eine Einführung in die berufliche Sozialisation. Weinheim, München: Juventa.

White, K.G. (2001). Forgetting functions. Animal Learning \& Behavior, 29.

Willcocks, L. (2011). Machiavelli, management and outsourcing: still on the learning curve. Strategic Outsourcing: An International Journal, 4(1), 5-12.

Wixted, J., \& Ebbesen, E. (1991). On the form of forgetting. American Psychological Society, 2(6), 409-415.

\section{Note}

Note 1. An inquiry regarding the measurement of the international work was answered by EgonZehnder International / Chicago as follows: "For the Global Board Index we used any/all public information available for a firm. We defined international work experience in one of two ways: 1) executive-level employment in a non-US market for a minimum period of time; and 2) responsibility for a particular facet of a company's international operations, even if said responsibility was exercised from a US-based location" (EgonZehnder International, 2010).

Table 1. International experience - different manifestations

\begin{tabular}{|c|c|c|}
\hline $\mathrm{Nr}$. & Sources of "International Experience" & Source \\
\hline 1. & International assignments & $\begin{array}{lllr}\text { Sullivan } & (1994) ; & \text { Roth } & (1995) \text {; } \\
\text { Sambarya } & (1996) ; & \text { Daily \&Certo\& } \\
\text { Dalton } & (2000) ; & \text { Carpenter \& } \\
\text { Fredrickson }(2001) & & \end{array}$ \\
\hline 2. & $\begin{array}{l}\text { Experience in an international function or function with } \\
\text { international responsibility }\end{array}$ & Roth (1995) \\
\hline 3. & Experience in an international division & $\begin{array}{l}\text { Sambarya (1996); Herrmann \&Datta } \\
\text { (2002) }\end{array}$ \\
\hline 4. & International work experience & $\begin{array}{l}\text { Bloodgood\&Sapienza (1996); } \\
\text { Tihany\&Ellstrand\& Daily \& Dalton } \\
\text { (2000); Carpenter \& Pollock \& Leary } \\
\text { (2003); Schmid \&Kretschmer (2005); } \\
\text { Takeuchi \&Tesluk\&Lepak(2005); Lee } \\
\text { \&Sukoco (2007) }\end{array}$ \\
\hline 5. & International schooling & Bloodgood\&Sapienza (1996) \\
\hline 6. & Work experience abroad & Reuber\& Fischer (1997) \\
\hline 7. & International sales experience & Reuber\& Fischer (1997) \\
\hline 8. & International education & $\begin{array}{l}\text { Tihany et al. (2000) ; Herrmann } \\
\text { \&Datta (2002); Carpenter et al. (2003); } \\
\text { Schmid \& Kretschmer (2005) }\end{array}$ \\
\hline 9. & $\begin{array}{l}\text { Responsibility for an international department (or work } \\
\text { abroad) }\end{array}$ & Wally \& Becerra (2001) \\
\hline 10. & Career international functional business experience & Athanassiou\& Nigh (2002) \\
\hline 11. & Experience in eight geographic regions & Athanassiou\& Nigh (2002) \\
\hline 12. & Foreign assignments & Herrmann \&Datta (2002) \\
\hline 13. & International experience diversity of TMT members & Greve\& Nielsen \&Ruigrok (2009) \\
\hline 14. & International nonwork experience & $\begin{array}{l}\text { Takeuchi et al. (2005); Lee \&Sukoco } \\
\text { (2007) }\end{array}$ \\
\hline 15. & International culture-specific experience & Takeuchi et al. (2005) \\
\hline
\end{tabular}

Source: Own illustrationaccording to Schmidt and Kretschmer (Schmid \&Kretschmer, 2005, p. 8)- modified 
Table 2. "Date of acquisition in years" of the six managers" international experience

\begin{tabular}{|c|c|c|c|c|c|c|}
\hline \multirow{2}{*}{ International Experience } & \multicolumn{6}{|c|}{$\begin{array}{l}\text { International Experience of notional managers } \\
\text { Length (Y) in years / Date of Acquisition in Years }\end{array}$} \\
\hline & A-1 & A-2 & A-3 & B-1 & B-2 & B-3 \\
\hline \multicolumn{7}{|l|}{ A. vocational preparation in ... } \\
\hline - UndergraduateStudent & $1 / 15$ & $1 / 15$ & 0 & $1 / 30$ & $1 / 30$ & 0 \\
\hline$\sum$ vocational preparation (years) & 1 & 1 & 0 & 1 & 1 & 0 \\
\hline \multicolumn{7}{|l|}{ B. occupation as ... } \\
\hline - Beginner & 0 & 0 & 0 & 0 & $2 / 25$ & 0 \\
\hline - Lower Level Manager & 0 & $3 / 10$ & 0 & $3 / 25$ & 0 & $3 / 15$ \\
\hline - Middle Level Manager & $2 / 5$ & 0 & $1 / 5$ & $4 / 15$ & $2 / 15$ & 0 \\
\hline - Top Level Manager & $1 / 1$ & 0 & $3 / 1$ & 0 & $3 / 5$ & $5 / 5$ \\
\hline$\sum$ occupation (years) & 3 & 3 & 4 & 7 & 7 & 8 \\
\hline$\sum$ Intern. Experience (years) & 4 & 4 & 4 & 8 & 8 & 8 \\
\hline
\end{tabular}

Source: Own illustration

Table 3. "Cultural distance" of the six managers" international experience

\begin{tabular}{|l|c|c|c|c|c|c|}
\hline & \multicolumn{5}{|c|}{ International Experience of notional managers } \\
\hline International Experience & A-1 & A-2 & A-3 & B-1 & B-2 & B-3 \\
\hline A. vocational preparation as... & & & & & & \\
\hline - Undergraduate student & $1 / 2.56$ & $1 / 2.56$ & 0 & $1 / 2.56$ & $1 / 2.56$ & 0 \\
\hline$\sum$ vocational preparation (years) & 1 & 1 & 0 & 1 & 1 & 0 \\
\hline & & & & & & \\
\hline B. occupation as ... & & & & & & \\
\hline - Beginner & 0 & 0 & 0 & 0 & $2 / 3,80$ & 0 \\
\hline - Lower Level Manager & 0 & $3 / 3.80$ & 0 & $3 / 0.03$ & 0 & $3 / 2.53$ \\
\hline - Middle Level Manager & $2 / 1.44$ & 0 & $1 / 1.44$ & $4 / 2.53$ & $2 / 2.53$ & 0 \\
\hline - Top Level Manager & $1 / 2.53$ & 0 & $3 / 2.53$ & 0 & $3 / 0.41$ & $5 / 1.44$ \\
\hline$\sum$ occupation (years) & 3 & 3 & 4 & 7 & 7 & 8 \\
\hline & & & & & & \\
\hline$\sum$ Intern. Experience (years) & 4 & 4 & 4 & 8 & 8 & 8 \\
\hline
\end{tabular}

Source: Own illustration

Table 4. International experience in "weighted and unweighted" form

\begin{tabular}{|l|c|c|c|c|c|c|}
\hline & \multicolumn{6}{|c|}{ International Experience of notional managers in years (Y) } \\
\hline International Experience & A-1 & A-2 & A-3 & B-1 & B-2 & B-3 \\
\hline$\sum$ vocational preparation (years) & 1 & 1 & 0 & 1 & 1 & 0 \\
\hline & & & & & & \\
\hline$\sum$ occupation (years) & 3 & 3 & 4 & 7 & 7 & 8 \\
\hline & & & & & & \\
\hline $\begin{array}{l}\text { International Experience } \\
\text { (years - unweighted) }\end{array}$ & 4 & 4 & 4 & 8 & 8 & 8 \\
\hline $\begin{array}{l}\sum \text { International Experience } \\
\text { (years - weighted) }\end{array}$ & 1.91 & 2.00 & 2.53 & 2.30 & 2.86 & 4.03 \\
\hline
\end{tabular}

Source: Own illustration 
Table 5. Overview-sample of 75 board members

\begin{tabular}{|c|c|c|c|}
\hline Member & $\mathrm{Y}_{\text {IE-Total }}$ & InEx WE-Norm & $\Delta$ Percent \\
\hline 1 & 1 & 0,52 & $-48 \%$ \\
\hline 2 & 1 & 0,45 & $-55 \%$ \\
\hline 3 & 1 & 0,69 & $-31 \%$ \\
\hline 4 & 1 & 0,56 & $-44 \%$ \\
\hline 5 & 2 & 1,56 & $-22 \%$ \\
\hline 6 & 2 & 1,25 & $-38 \%$ \\
\hline 7 & 3 & 1,45 & $-52 \%$ \\
\hline 8 & 3 & 1,23 & $-59 \%$ \\
\hline 9 & 3 & 2,03 & $-32 \%$ \\
\hline 10 & 3 & 1,32 & $-56 \%$ \\
\hline 11 & 3 & 1,21 & $-60 \%$ \\
\hline 12 & 4 & 2,13 & $-47 \%$ \\
\hline 13 & 4 & 3,01 & $-25 \%$ \\
\hline 14 & 4 & 1,21 & $-70 \%$ \\
\hline 15 & 4 & 1,59 & $-60 \%$ \\
\hline 16 & 4 & 2,01 & $-50 \%$ \\
\hline 17 & 4 & 1,98 & $-51 \%$ \\
\hline 18 & 4 & 3,05 & $-24 \%$ \\
\hline 19 & 4 & 1,68 & $-58 \%$ \\
\hline 20 & 4 & 2,45 & $-39 \%$ \\
\hline 21 & 5 & 2,12 & $-58 \%$ \\
\hline 22 & 5 & 2,02 & $-60 \%$ \\
\hline 23 & 5 & 1,89 & $-62 \%$ \\
\hline 24 & 6 & 2,91 & $-52 \%$ \\
\hline 25 & 6 & 3,14 & $-48 \%$ \\
\hline 26 & 7 & 5,12 & $-27 \%$ \\
\hline 27 & 7 & 2,63 & $-62 \%$ \\
\hline 28 & 8 & 3,95 & $-51 \%$ \\
\hline 29 & 8 & 2,98 & $-63 \%$ \\
\hline 30 & 8 & 2,31 & $-71 \%$ \\
\hline 31 & 8 & 2,69 & $-66 \%$ \\
\hline 32 & 8 & 2,45 & $-69 \%$ \\
\hline 33 & 8 & 5,53 & $-31 \%$ \\
\hline 34 & 8 & 2,32 & $-71 \%$ \\
\hline 35 & 8 & 2,85 & $-64 \%$ \\
\hline 36 & 9 & 2,13 & $-76 \%$ \\
\hline 37 & 9 & 3,01 & $-67 \%$ \\
\hline 38 & 9 & 4,85 & $-46 \%$ \\
\hline 39 & 9 & 4,12 & $-54 \%$ \\
\hline 40 & 9 & 2,68 & $-70 \%$ \\
\hline 41 & 9 & 5,12 & $-43 \%$ \\
\hline 42 & 10 & 3,12 & $-69 \%$ \\
\hline 43 & 10 & 3,14 & $-69 \%$ \\
\hline 44 & 10 & 4,01 & $-60 \%$ \\
\hline 45 & 12 & 6,85 & $-43 \%$ \\
\hline
\end{tabular}

\begin{tabular}{|c|c|c|c|}
\hline Member & $\mathrm{Y}_{\text {IE-Total }}$ & InEx WE-Norm & $\Delta$ Percent \\
\hline 46 & 12 & 4,15 & $-65 \%$ \\
\hline 47 & 12 & 5,02 & $-58 \%$ \\
\hline 48 & 13 & 4,15 & $-68 \%$ \\
\hline 49 & 13 & 4,54 & $-65 \%$ \\
\hline 50 & 13 & 4,12 & $-68 \%$ \\
\hline 51 & 13 & 7,51 & $-42 \%$ \\
\hline 52 & 13 & 4,14 & $-68 \%$ \\
\hline 53 & 14 & 6,53 & $-53 \%$ \\
\hline 54 & 14 & 4,52 & $-68 \%$ \\
\hline 55 & 15 & 5,36 & $-64 \%$ \\
\hline 56 & 15 & 7,12 & $-53 \%$ \\
\hline 57 & 15 & 6,13 & $-59 \%$ \\
\hline 58 & 15 & 5,89 & $-61 \%$ \\
\hline 59 & 16 & 7,01 & $-56 \%$ \\
\hline 60 & 16 & 8,56 & $-47 \%$ \\
\hline 61 & 16 & 3,89 & $-76 \%$ \\
\hline 62 & 16 & 4,15 & $-74 \%$ \\
\hline 63 & 18 & 5,68 & $-68 \%$ \\
\hline 64 & 19 & 5,87 & $-69 \%$ \\
\hline 65 & 20 & 6,10 & $-70 \%$ \\
\hline 66 & 20 & 6,87 & $-66 \%$ \\
\hline 67 & 20 & 14,12 & $-29 \%$ \\
\hline 68 & 21 & 12,75 & $-39 \%$ \\
\hline 69 & 22 & 5,54 & $-75 \%$ \\
\hline 70 & 27 & 8,12 & $-70 \%$ \\
\hline 71 & 28 & 12,10 & $-57 \%$ \\
\hline 72 & 30 & 12,90 & $-57 \%$ \\
\hline 73 & 30 & 13,14 & $-56 \%$ \\
\hline 74 & 31 & 9,02 & $-71 \%$ \\
\hline 75 & 37 & 14,15 & $-62 \%$ \\
\hline
\end{tabular}

Explanation:

N

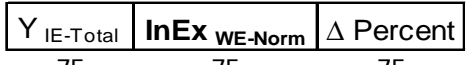

$\begin{array}{llll}\text { Range } & 36 & 13,7 & 54 \%\end{array}$

Minimum $1 \quad 0,45 \quad-22 \%$

Maximum $37 \quad 14,15 \quad-76 \%$

$\begin{array}{llll}\text { Mean } & 10,98 & 4,46 & -56 \%\end{array}$

S. Deviatic $8 \quad 3,3$

Variance $\quad 64,01 \quad 10,89$

\section{Source:}

DAX / M-DAX vitas of Board Member 2009

Different sources - see references 